\title{
A confidential enquiry into emergency hospital admissions on the Isle of Wight, UK
}

\author{
Mark Denman-Johnson, Paul Bingham, Steve George
}

\begin{abstract}
Objectives-To quantify the proportion of potentially avoidable emergency short term admissions to hospital and to identify ways in which they could have been avoided.
\end{abstract}

Design-Confidential enquiry by peer review group.

Setting-St Mary's Hospital, Newport, Isle of Wight.

Subjects-All emergency, short term admissions (discharged home within five days) to medicine, general surgery, orthopaedics, gynaecology, ENT, and ophthalmology specialties for 28 ( 24 hour) days over a six month period in 1994. Main outcome measures-Appropriateness of admissions decided by the peer group, the peer group's opinion of ideal management, and the patients' views on the appropriateness of their admission.

Results-Altogether 139 cases satisfied the inclusion criteria. Complete data were collected on 123 cases and the peer group considered 81 in the time available. Twenty one of the 81 cases were judged "potentially avoidable". These represent $9.5 \%$ (95\% CI $6.3 \%, 13.5 \%$ ) of short term admissions to the specialties studied. The peer group considered that seven of 10 patients referred by a general practitioner (GP) could have been managed by the GP alone and that the remaining three had been referred appropriately but need not have been admitted had a consultant opinion been available in the accident and emergency (A\&E) department. Two of the 10 would have required home support to avoid hospital admission. Five of 11 patients who referred themselves to $A \& E$ could have been discharged home without admission and without recourse to a specialist opinion. The remaining six could have been discharged had a consultant opinion been available in A\&E.

Conclusions-Urgent consultant opinion, either in A\&E or in an outpatient clinic, would have prevented most of these inappropriate admissions, and home support would have expedited the ability to discharge some patients. Further research into the costs and benefits of methods for providing these services is needed urgently.

(f Epidemiol Community Health 1997;51:386-390)

Concern has been expressed about the rise in emergency admissions to hospitals in the UK. In 1993-94, emergency admissions across the
UK rose by between 5 and $25 \% .^{1}$ A 1994 symposium of the National Association of Health Authorities and Trusts (NAHAT) listed several possible explanations including demographic changes, overflow from planned elective treatment, increasingly defensive medicine, and increased expectations of both patients and general practitioners (GPs). ${ }^{2}$ It is widely assumed that much of this rise "comprises admissions that are inappropriate". Problems of inappropriate usage of acute beds have been described in five areas: admission, placement, (length of) stay, discharge, and bed availability and management. ${ }^{3}$

Several studies have focused upon "bed blockers"-long term patients who no longer need acute care beds - as inappropriate users of medical beds. ${ }^{4}$ However, the study of prevalent cases gives rise to length-time bias which may overemphasise their contribution to this problem. ${ }^{5}$ In 1993, the number of emergency admissions to St Mary's Hospital, Newport, Isle of Wight increased by $20 \%$ compared with the previous year. An initial study using routinely collected incident data showed that the 1993 increase was largely composed of patients admitted for a short period of four days or less whose discharge diagnosis was often assigned to an ill defined ICD9 category (Isle of Wight Health Authority-personal communication). Given this finding we decided to try to quantify the proportion of potentially avoidable, emergency short term admissions to St Mary's Hospital and to identify ways in which these could have been avoided.

\section{Method}

Several previous studies have attempted to classify hospital admissions as "appropriate" or "not appropriate" using a standard instrument-usually the Rand Corporation instrument, ${ }^{6-9}$ or the Oxford bed study instrument. ${ }^{41011}$ Other similar instruments have also been used. ${ }^{12-14}$ These instruments have, however, attracted criticism. The Rand instrument has been criticised for omitting any reference to resource usage in its definition of appropriateness and for ignoring the individuality of the patient. ${ }^{15}$ The Oxford instrument has been criticised for making the assumptions that all investigations that patients have are appropriate and that patients need to be admitted to hospital to have these tests, thus leading to an underestimate of inappropriate admission. ${ }^{10}$ To counter the problems brought about by the use of standardised instruments, we decided to conduct this study using methods derived from various confidential enquiries- 
that is, to use an expert panel to consider the necessity of individual admissions rather than the effectiveness of different medical and surgical procedures.

A peer review group was set up which comprised a general surgeon, a general physician, two GPs from fundholding group practices, and a senior social worker. All members worked locally, on the Isle of Wight. The group was facilitated by the researcher (MDJ) and a consultant in public health medicine (PB). The use of a peer review group allowed us to identify specific factors which might have prevented admission in some cases. The method has been used recently by other workers in the same area, ${ }^{1617}$ although our group included representation from social services as well as medical provider groups.

All emergency admissions to the specialties of medicine, general surgery, orthopaedics, gynaecology, ENT, and ophthalmology were recorded for 28 ( 24 hour) days over six months in 1994. Because of their fundamentally different working patterns, paediatric and obstetric wards were excluded from the study. Days were selected to give an equal number of different days of the week in the sample. During each study day the researcher visited the wards of St Mary's on at least two occasions (early morning and late evening), and usually more often. In an initial screen, patients were identified whose admission was likely to last no more than five days, a period chosen to reflect the rise in admissions of four days or fewer found in the pilot study. The process used for screening patients included interviewing every patient admitted to hospital who was potentially there for a short stay. Those who proceeded to surgery or whose stay would obviously exceed five days (eg patients with myocardial infarction, who would routinely be admitted for seven days) were excluded at this stage. Patients whose stay eventually exceeded five days, patients who died during the admission, and those who were transferred to another hospital were also excluded from further analysis. This process meant that a large number of people were interviewed who were eventually excluded from the study. Our researcher tried to validate the data collected against the routinely collected hospital database but found that the system recorded far fewer short term admissions than he did and therefore abandoned this.

Table 1 Criteria defined by the peer group as constituting medical or surgical reasons for emergency hospital admission. Admissions that did not satisfy any of these criteria were deemed "potentially avoidable"

1. A condition requiring ventilation

2. A potentially life threatening condition that may require immediate treatment and/or observation (except for a single observation or treatment manageable at home)

3. A condition requiring intravenous infusion or repeated intravenous injection

4. Severe pain requiring more than one intramuscular injection

5. A condition requiring care of a major wound (surgical or traumatic) or drainage

6. A condition requiring continuous monitoring of vital signs (including cardiac monitoring)

7. A condition requiring at least once daily medical monitoring by a doctor on an ongoing basis, but excluding a simple return visit

8. A condition requiring urgent therapeutic or investigative procedure (required to be done within 5 days) that cannot be carried out as a day case

9. A condition requiring spinal traction

10. Other indication for admission accepted by the peer group
KEY POINTS

- $9.5 \%$ of short term emergency hospital admissions in this study were considered to be potentially avoidable by a peer review group.

- A senior specialist opinion in the $A \& E$ department would have prevented hospital admission in most potentially avoidable admissions.

- Some patients could have been discharged home if home support had been available.

For each case the researcher collected the referral letter, initial nursing observations and immediate laboratory tests, and the record made by the admitting doctor and he made photocopies. This was followed by a semistructured interview with the patient, usually within one day of admission, during which a detailed history of the complaint leading to the present admission was taken, the extent of available home support was ascertained, and the patient's social circumstances and their view of whether their admission could have been avoided were explored. At this interview permission was also sought to contact the patient and their GP after their discharge home. The researcher then contacted the patient one month after discharge and conducted a further interview to monitor the patient's progress since discharge. The patient's GP was also contacted to ascertain whether they had had any contact with the patient after discharge from hospital and, if so, the reasons for the contact. The views of the GP on the necessity of the original admission were also gathered at this stage. All data gathered were anonymised before presentation to the peer review group.

Cases were selected for presentation to the peer review group in the order in which they had been admitted to hospital. The group considered data in two stages. For each case they first considered the data available to, and the record made by, the admitting doctor, which included the time and date upon which the patient presented. Second they considered the data collected by the researcher at the first interview with the patient, plus copies of all hospital inpatient records relating to the admission. The peer group devised, by consensus, a series of nine criteria, plus one "open criterion". One or more of these had to be satisfied before a patient could be considered as having a medical or surgical reason for admission (table 1). These criteria were deliberately chosen to be broader than those in standardised instruments, and therefore to be more flexible in their application. Admissions which did not satisfy any of the nine predefined criteria and for which there was no special circumstance accepted by the group as a 10th criterion were deemed "potentially avoidable". The peer group then assessed the ideal management of these patients and classified them according to their source of referral. The peer group also reviewed the need for social support in each 
Table 2 Derivation of estimate of proportion of all emergency admissions to St Mary's Hospital, Isle of Wight in specialties studied classifiable as "potentially avoidable" $(x)$

$\mathrm{x}=\quad \begin{gathered}\text { Estimated proportion of cases meeting inclusion criteria } \\ \text { which could be classified as "potentially avoidable" }\end{gathered}$
All cases studied
or
$x=\frac{0.26 \times 139}{139+240}=0.095(9.5 \%)$

case and the contribution this had made towards the admission.

For all cases the peer group reached a decision on appropriateness of admission based on information available to the admitting doctor. On no occasion did the group change its decision when information collected at a later date by the research worker was introduced, although this latter information did enable them to identify patients who would have required support to enable them to stay at home.

\section{Results}

During the study period 139 cases satisfied the inclusion criteria and complete data were collected for 123 (88\%) of these. Data were not collected on the other 16 cases for a variety of reasons, most commonly that their stay was for a few hours only and they had been admitted and discharged between visits made to the ward by the research worker. Over the same period, 240 emergency admissions did not meet the initial inclusion criteria. The research worker collected data on 37 out of 240 who seemed likely to meet the inclusion criteria initially, but eventually did not.

The project was labour intensive. Funding was available for six meetings only of the peer review group. Each meeting lasted $2 \frac{1}{2}$ hours, and the group was able to consider only 81 of the 123 cases in the time available. We have no reason, however, to believe that the cases considered are in any way unrepresentative. Of the 81 cases considered, $21(26 \%)$ did not satisfy medical or surgical criteria for admission and were classified as potentially avoidable. Assuming that the distribution of cases who did not satisfy medical or surgical criteria for admission remained the same throughout the whole 139 cases and that admission of the 240 patients who did not satisfy the inclusion criteria was unavoidable, $9.5 \%$ of emergency admissions to St Mary's were potentially avoidable in the specialties studied (95\% CI $6.3 \%$, $13.46 \%)$. The derivation of this figure is given in table 2. No significant difference existed between cases classified as potentially avoidable or not potentially avoidable in terms of either mean age (50.57 years $\mathrm{v} 51.43$ years, $t$ test: $\mathrm{p}=0.86$ ) or gender distribution (male/female $12 / 9$ v 37/23, $\left.\chi^{2} 0.13: p=0.72\right)$.

Table 3 Classification of hospital admissions deemed to be "potentially avoidable" by peer group: cases referred by GP and judged as "inappropriate referral, could have been managed at home" $(n=7)$

\begin{tabular}{|c|c|c|c|c|c|c|}
\hline \multirow[t]{2}{*}{$\begin{array}{l}\text { Case } \\
\text { no }\end{array}$} & \multirow[t]{2}{*}{$\begin{array}{l}\text { Age } \\
(y)\end{array}$} & \multirow[t]{2}{*}{ Sex } & \multirow[t]{2}{*}{ Clinical presentation } & \multirow[t]{2}{*}{$\begin{array}{l}\text { Peer group view on } \\
\text { alternative management }\end{array}$} & \multicolumn{2}{|c|}{$\begin{array}{l}\text { View of necessity of admission sought one } \\
\text { month after discharge }\end{array}$} \\
\hline & & & & & Patient & $G P$ \\
\hline 5 & 79 & $\mathbf{M}$ & $\begin{array}{l}\text { Paraphimosis easily reduced } \\
\text { after admission by surgical } \\
\text { registrar. }\end{array}$ & $\begin{array}{l}\text { GP should have examined the } \\
\text { patient. Formal assessment by } \\
\text { surgical registrar should have } \\
\text { taken place before admission. }\end{array}$ & $\begin{array}{l}\text { Admission avoidable } \\
\text { (Patient demented: view } \\
\text { given by nursing home } \\
\text { staff). }\end{array}$ & Admission avoidable. \\
\hline 46 & 43 & $\mathbf{M}$ & $\begin{array}{l}\text { Hyperglycaemia consequent } \\
\text { to steroid treatment. Patient } \\
\text { felt well. }\end{array}$ & $\begin{array}{l}\text { Next day appointment in } \\
\text { diabetes clinic. Supported by } \\
\text { wife at home. }\end{array}$ & $\begin{array}{l}\text { Admission avoidable if had } \\
\text { seen GP earlier. }\end{array}$ & Admission indicated. \\
\hline 57 & 57 & $\mathrm{~F}$ & $\begin{array}{l}\text { Possible sub-acute bacterial } \\
\text { endocarditis-symptoms } \\
\text { getting better. }\end{array}$ & Urgent outpatient appointment. & Admission avoidable. & $\begin{array}{l}\text { Referral indicated-would have been } \\
\text { happy if discharged once seen. }\end{array}$ \\
\hline 64 & 34 & $\mathrm{~F}$ & $\begin{array}{l}\text { Long standing abdominal } \\
\text { pain-patient concerned. }\end{array}$ & Urgent outpatient appointment. & Admission indicated. & $\begin{array}{l}\text { Admission indicated, although } \\
\text { laparoscopy performed within a } \\
\text { month, was normal. }\end{array}$ \\
\hline $71^{*}$ & 23 & $\mathrm{~F}$ & $\begin{array}{l}\text { Possible appendicitis, but } \\
\text { minimal signs. }\end{array}$ & $\begin{array}{l}\text { GP review of patient at home if } \\
\text { support available. }\end{array}$ & $\begin{array}{l}\text { Admission avoidable with } \\
\text { home support. }\end{array}$ & $\begin{array}{l}\text { Referral indicated-would have been } \\
\text { happy if discharged once seen. }\end{array}$ \\
\hline 73 & 72 & $\mathbf{M}$ & $\begin{array}{l}\text { Recurrent haematuria after } \\
\text { TURP. }\end{array}$ & Urgent outpatient review. & Admission avoidable. & $\begin{array}{l}\text { Admission indicated-but had not } \\
\text { seen patient since discharge. }\end{array}$ \\
\hline 74 & 18 & $\mathbf{M}$ & $\begin{array}{l}\text { Possible appendicitis, but } \\
\text { minimal signs. }\end{array}$ & GP review of patient at home. & Admission avoidable. & $\begin{array}{l}\text { Referral indicated-would have been } \\
\text { happy if discharged once seen. }\end{array}$ \\
\hline
\end{tabular}

* Cases where social support was not already present and where this would have been required to avoid admission.

TURP $=$ transurethral resection of prostate.

Table 4 Classification of hospital admissions deemed to be "potentially avoidable" by peer group: cases referred by GP and judged as "appropriate referral, but admission could have been avoided if a senior medical/surgical opinion had been available on presentation to the hospital" ( $n=3$ )

\begin{tabular}{|c|c|c|c|c|c|c|}
\hline \multirow[t]{2}{*}{$\begin{array}{l}\text { Case } \\
\text { no }\end{array}$} & \multirow[t]{2}{*}{$\begin{array}{l}\text { Age } \\
(y)\end{array}$} & \multirow[t]{2}{*}{ Sex } & \multirow[t]{2}{*}{ Clinical presentation } & \multirow[t]{2}{*}{$\begin{array}{l}\text { Peer group view on } \\
\text { alternative management }\end{array}$} & \multicolumn{2}{|c|}{$\begin{array}{l}\text { View of necessity of admission sought one } \\
\text { month after discharge }\end{array}$} \\
\hline & & & & & Patient & $G P$ \\
\hline $29^{*}$ & 67 & $M$ & $\begin{array}{l}\text { Possible appendicitis: had started to } \\
\text { improve when seen by GP-minimal } \\
\text { signs by time of admission. }\end{array}$ & $\begin{array}{l}\text { Discharge home if support } \\
\text { available. GP review if } \\
\text { symptoms worsened. }\end{array}$ & Not contactable. & $\begin{array}{l}\text { Referral indicated-would } \\
\text { have been happy if discharged } \\
\text { once seen. }\end{array}$ \\
\hline 40 & 25 & F & $\begin{array}{l}\text { Possible ectopic pregnancy- } \beta \text { HCG } \\
\text { negative. Had started to improve } \\
\text { when seen by GP. }\end{array}$ & $\begin{array}{l}\text { Discharge home. GP review if } \\
\text { symptoms return. }\end{array}$ & Admission indicated. & $\begin{array}{l}\text { Referral indicated-would } \\
\text { have been happy if discharged } \\
\text { once ectopic excluded. }\end{array}$ \\
\hline 49 & 82 & $M$ & $\begin{array}{l}\text { Possible intestinal obstruction } \\
\text { excluded. Diagnosis of urinary tract } \\
\text { infection made. }\end{array}$ & $\begin{array}{l}\text { Discharge home. GP review } \\
\text { following day. }\end{array}$ & Admission indicated. & $\begin{array}{l}\text { Referral indicated-would } \\
\text { have been happy if discharged } \\
\text { once obstruction excluded. }\end{array}$ \\
\hline
\end{tabular}

* Cases where social support was not already present and where this would have been required to avoid admission. 
Table 5 Classification of admissions deemed to be "potentially avoidable" by peer group: cases self referring to AE'E judged as "could have been managed and discharged without recourse to a specialist opinion" $(n=5)$

\begin{tabular}{|c|c|c|c|c|c|c|}
\hline \multirow[t]{2}{*}{$\begin{array}{l}\text { Case } \\
\text { no }\end{array}$} & \multirow[t]{2}{*}{$\begin{array}{l}\mathrm{Age} \\
(y)\end{array}$} & \multirow[t]{2}{*}{$\operatorname{Sex}$} & \multirow[t]{2}{*}{ Clinical presentation } & \multirow[t]{2}{*}{$\begin{array}{l}\text { Peer group view on } \\
\text { alternative management }\end{array}$} & \multicolumn{2}{|c|}{$\begin{array}{l}\text { View of necessity of admission sought one } \\
\text { month after discharge }\end{array}$} \\
\hline & & & & & Patient & $G P$ \\
\hline $26^{*}$ & 48 & $\mathbf{M}$ & $\begin{array}{l}\text { Faint after a sauna: minor head injury. } \\
\text { No indication to admit under head } \\
\text { injury protocol. }\end{array}$ & $\begin{array}{l}\text { Discharge home if support } \\
\text { available. }\end{array}$ & $\begin{array}{l}\text { Admission avoidable if home } \\
\text { support available. }\end{array}$ & $\begin{array}{l}\text { Not seen patient since } \\
\text { discharge. }\end{array}$ \\
\hline $32^{*}$ & 84 & $\mathbf{F}$ & $\begin{array}{l}\text { Fall resulting in occipital haematoma. } \\
\text { No indication to admit under head } \\
\text { injury protocol. }\end{array}$ & $\begin{array}{l}\text { Discharge home if support } \\
\text { available. }\end{array}$ & Not contactable. & $\begin{array}{l}\text { Not seen patient since } \\
\text { discharge. }\end{array}$ \\
\hline $36^{*}$ & 25 & $\mathbf{M}$ & $\begin{array}{l}\text { Heavy gate fell on patient. Bruising } \\
\text { but no bony injury. }\end{array}$ & $\begin{array}{l}\text { Discharge home if support } \\
\text { available. }\end{array}$ & $\begin{array}{l}\text { Not contacted (patient } \\
\text { resident on mainland). }\end{array}$ & $\begin{array}{l}\text { Not contacted (patient } \\
\text { resident on mainland). }\end{array}$ \\
\hline $89^{*}$ & 77 & $\mathrm{~F}$ & $\begin{array}{l}\text { Minor head injury. No indication to } \\
\text { admit under head injury protocol. }\end{array}$ & $\begin{array}{l}\text { Discharge home if support } \\
\text { available. }\end{array}$ & $\begin{array}{l}\text { Patient did not feel able to } \\
\text { comment. }\end{array}$ & $\begin{array}{l}\text { Not seen patient since } \\
\text { discharge. }\end{array}$ \\
\hline $105^{*}$ & 74 & $\mathbf{F}$ & Epistaxis stopped with balloon. & $\begin{array}{l}\text { Discharge home if support } \\
\text { available. }\end{array}$ & Admission indicated. & Admission avoidable. \\
\hline
\end{tabular}

* Cases where social support was not already present and where this would have been required to avoid admission.

Table 6 Classification of cases deemed to be "potentially avoidable" by peer group: cases self referring to AE E and judged as "admission could have been avoided if a senior medical/surgical opinion had been available on presentation to the hospital" $(n=6)$

\begin{tabular}{|c|c|c|c|c|c|c|}
\hline \multirow[t]{2}{*}{$\begin{array}{l}\text { Case } \\
\text { no }\end{array}$} & \multirow[t]{2}{*}{$\begin{array}{l}\text { Age } \\
(y)\end{array}$} & \multirow[t]{2}{*}{ Sex } & \multirow[t]{2}{*}{ Clinical presentation } & \multirow[t]{2}{*}{$\begin{array}{l}\text { Peer group view on } \\
\text { alternative management }\end{array}$} & \multicolumn{2}{|c|}{$\begin{array}{l}\text { View of necessity of admission sought one } \\
\text { month after discharge }\end{array}$} \\
\hline & & & & & Patient & $G P$ \\
\hline 1 & 37 & $\mathbf{F}$ & $\begin{array}{l}\text { Return visit to A\&E with abdominal } \\
\text { pain. Minimal signs. Previous } \\
\text { appendicectomy. Pregnancy excluded. }\end{array}$ & $\begin{array}{l}\text { Discharge home. Outpatient review } \\
\text { following day. }\end{array}$ & Not contactable. & Not registered with GP. \\
\hline 20 & 34 & $\mathbf{F}$ & $\begin{array}{l}\text { Long standing menorrhagia. Presented } \\
\text { with "heavy bleeding". Haemoglobin } \\
\text { not measured on admission. }\end{array}$ & Outpatient review. & Admission avoidable. & $\begin{array}{l}\text { Not seen patient since } \\
\text { discharge. }\end{array}$ \\
\hline 27 & 17 & $\mathbf{M}$ & $\begin{array}{l}\text { Blood in ear two days following head } \\
\text { injury. }\end{array}$ & $\begin{array}{l}\text { Full ENT examination of ear on } \\
\text { presentation rather than the following } \\
\text { day (old blood-no aural damage } \\
\text { seen). No indication to admit. }\end{array}$ & $\begin{array}{l}\text { Admission avoidable } \\
\text { (surprised to have } \\
\text { been admitted). }\end{array}$ & $\begin{array}{l}\text { Not seen patient since } \\
\text { discharge. }\end{array}$ \\
\hline 41 & 67 & $\mathbf{M}$ & $\begin{array}{l}\text { Reflux oesphagitis. Myocardial } \\
\text { infarction included in differential } \\
\text { diagnosis but not acted upon. Patient } \\
\text { not admitted to coronary care unit. }\end{array}$ & Discharge home. & Admission indicated. & $\begin{array}{l}\text { Not seen patient since } \\
\text { discharge. }\end{array}$ \\
\hline 72 & 35 & $\mathbf{M}$ & $\begin{array}{l}\text { Epididymo-orchitis. Started on } \\
\text { antibiotics by GP. }\end{array}$ & $\begin{array}{l}\text { Discharge home. GP review following } \\
\text { day. }\end{array}$ & $\begin{array}{l}\text { Admission indicated } \\
\text { (and felt discharged } \\
\text { too early). }\end{array}$ & Admission indicated. \\
\hline 102 & 64 & $\mathbf{M}$ & Thrombosed pile. & $\begin{array}{l}\text { Incise or local treatment then } \\
\text { discharge home. }\end{array}$ & Admission indicated. & $\begin{array}{l}\text { Avoidable-would have } \\
\text { been happy to treat at } \\
\text { home if consulted. }\end{array}$ \\
\hline
\end{tabular}

The classification of the 21 potentially avoidable cases according to their source of referral and according to the peer group's assessment of ideal management is given in tables 3 to 6 .

Of the 10 cases referred by a GP, the peer group considered that seven could have been managed by the GP without recourse to hospital admission (table 3 ). Of these, four cases could have been managed with an urgent, next day outpatient appointment; two cases could have been managed by a return GP visit later that day to re-evaluate signs and symptoms; and in one case the GP should have examined and treated the patient at their initial consultation. When contacted a month after discharge, six of the seven GPs still felt that emergency referral had been indicated but three stated that if the patient had been seen by a consultant in the accident and emergency (A\&E) department they would have been happy to look after the patient at home. The peer group considered that three cases were referred appropriately by a GP (table 4 ), but that admission could have been avoided if a consultant opinion from the relevant specialty had been available in the accident and emergency (A\&E) department. In each case the referring GP said that they would have been happy to manage the patient at home if the patient had been seen by an appropriate consultant at $A \& E$. Two of the 10 patients referred by GPs would have required home support if hospital admission were to have been avoided.

The peer group considered that five of the 11 patients who referred themselves to the A\&E department could have been discharged home without admission and without recourse to a specialist opinion (table 5). Six further cases could have been discharged had a consultant opinion been available in casualty (table 6). Of these 11 cases only three had seen their GP since discharge from hospital. Only one of these GPs said they would have been happy to look after the patient at home had they been consulted. Five of these 11 cases could have been discharged home only if given home support.

The peer group also noted that a few patients had had symptoms for days or weeks but had delayed presenting to their GP.

Patients were asked on two occasions whether they felt their admission could have been avoided: when they were first interviewed by the project worker (on the day of admission) and then when they were telephoned a month after discharge. These results are summarised in table 7. Perhaps the most interesting finding is that six patients considered that their admission could have been avoided and that they were of this view both at admission and one month after discharge. 
Table 7 Patients'view at hospital admission and one month after hospital discharge home on whether their admission could have been avoided

\begin{tabular}{|c|c|c|c|c|c|}
\hline & & \multicolumn{4}{|c|}{ Patient's view at admission } \\
\hline & & $\begin{array}{l}\text { Admission } \\
\text { necessary }\end{array}$ & $\begin{array}{l}\text { Admission could } \\
\text { have been avoided }\end{array}$ & $\begin{array}{l}\text { Patient } \\
\text { uncertain }\end{array}$ & Total \\
\hline \multirow[t]{5}{*}{$\begin{array}{l}\text { View one } \\
\text { month later }\end{array}$} & $\begin{array}{l}\text { Admission } \\
\text { necessary }\end{array}$ & 5 & 1 & 2 & 8 \\
\hline & $\begin{array}{l}\text { Admission could } \\
\text { have been avoided }\end{array}$ & 2 & 6 & 0 & 8 \\
\hline & Patient uncertain & 1 & 1 & 1 & 3 \\
\hline & Not contactable & 1 & 0 & 1 & 2 \\
\hline & Total & 9 & 8 & 4 & 21 \\
\hline
\end{tabular}

\section{Discussion}

A GP referring a patient often needs a consultant's opinion, not a hospital admission. In nine of the 21 cases deemed potentially avoidable, a consultant medical or surgical opinion in the $A \& E$ department would have prevented the admission. The provision of next day, urgent outpatient appointments, which are currently not readily available, would have obviated the need for admission in a further six cases in our study.

One third of the 21 cases could have been discharged home if there had been adequate arrangements for social support. Patients requiring social support were not generally elderly or highly dependent. Most required only that someone was available to check that their condition did not deteriorate. However, it may be that the inability of health and community services to cope with changing demand has partly caused the rise in emergency admissions. ${ }^{18}$ The peer group felt also that in some cases GPs should have been prepared to make return home visits to patients in whom signs and symptoms were still evolving. However, GPs might not prove easy to persuade that they should provide such repeat visits. Out of hours workload in general practice has increased fourfold over the last 25 years. ${ }^{19-21}$

Our overall projection that $9.5 \%$ of acute admissions to hospital are avoidable must be interpreted in the knowledge that our peer group was not blinded to the eventual outcome of the cases studied, knew that they had been discharged within five days, and knew that they did not die during admission. Nevertheless, it is in line with contemporary studies, some of which have used similar methods. ${ }^{11} 1617$ Our principal finding is that senior medical and surgical opinions need to be more readily available in an emergency situation. Such provision in the $A \& E$ department would mean a change in the traditional work practices of most consultants but might prove cost effective and not too onerous if a consultant were called only when really necessary. Intervention studies comparing the costs and benefits of providing such opinions are required urgently. Re-organisation in the outpatient department would not mean such a radical change in work practices but might require more spare capacity, and therefore resources. Although some have suggested that such substitution could result in overall cost savings, they also found that such savings were likely to be small. ${ }^{16}$ Further work is also required to evaluate the contribution of other providers, both from primary care and social services, in providing home support and to compare the costs of organising this support with those of a short inpatient admission.

There are undoubtedly many other imaginative ways in which the emergency primary/ secondary interface could be improved. Only by exploring those ways, improving arrangements for "a quick opinion", and optimising home support arrangements can we hope to stem the rising tide of emergency admissions.

We thank all the members of the project steering group and especially of the project peer group for their hard work during this study and Dr Chris Spencer-Jones and Professor John Gabbay for their comments on the manuscript.

1 Butler P. Mystery rise in emergency admissions hits hospitals. Health Serv f 1994;29 September:3.

2 National Association of Health Authorities and Trusts. Emergency admissions: managing the rising trend. Briefing 74. Birmingham: NAHAT, 1994.

3 Audit Commission. Lying in wait: the use of medical beds in acute hospitals. London: HMSO, 1992.

4 Victor C, Nazareth B, Hudson M, Fulop $N$. The inappropriate use of acute hospital beds in an inner London district health authority. Health Trends 1993;25(3):94-97.

5 Last JM. A dictionary of epidemiology. 2nd Ed. Oxford, Oxford University Press, 1988.

6 Chassin MR, Kosecoff J, Park RE, et al Does inappropriate use explain geographic variations in the use of health care services? FAMA 1987;258:2533-37.

7 Brook RH, Chassin MR, Fink A, Solomon DH, Kosecoff J, Park RE. A method for the detailed assessment of the appropriateness of medical technologies. Int $\mathfrak{F}$ Tech Assess Health Care 1986;2:53-63.

$8 \mathrm{Kahn}$ KLO, Kosecoff J, Chassin MR, et al. Measuring the appropriateness of the use of a procedure: can we do it? appropriateness of the use

9 Park RE, Fink A, Brook RH. Physician evaluation of appropriate indications for six medical and surgical propropriate indications for six medical and surg

10 Anderson P, Meara J, Brodhurst S. Use of hospital beds: a cohort study of admissions to a provincial teaching hospital. BMF 1988;297:910-12

11 Victor CR, Khakoo AA. Is hospital the right place? A survey of inappropriate admissions to an inner London NHS Trust. F Public Health Med 1994;16(3):286-90.

12 Gertman PM, Restuccia JD. The appropriateness evaluation protocol: a technique for assessing unnecessary days of hospital care. Med Care 1981;19:855-70.

13 Restuccia JD, Gertman PM, Dayno SJ, Kreger BE, Lenhar GM. The appropriateness of hospital use. Health Affairs 1984;3:130-38.

14 Kellett J. Appropriateness of admissions to the medical wards of an Irish County Hospital. F Irish Coll Physicians wards of an Irish County Hosp

15 Hopkins A for a Working Group for the Director of Research and Development of the NHS Management Executive. and Development of the NHS Management Executive. What do we mean by appropri

16 Coast J, Inglis A, Morgan K, Gray S, Kammerling M, Frankel S. The hospital admissions study in England: are there alternatives to emergency hospital admission? $\mathcal{f}$ Epidemiol Community Health 1995;49:194-99.

17 Coast J, Inglis A, Frankel S. Alternatives to hospital care: what are they and who should decide? $B M \mathcal{F}^{\prime} 1996 ; 312$ : $162-66$.

18 Kendrick S. Emergency admissions: what is driving the increase? Health Serv $\mathcal{F}$ 1995;4 May:26-28.

19 Hallam L. Primary medical care outside normal working hours: review of published work. $B M 7$ 1994;308:249-53.

20 Beecham L. Home visits will fall with new GP scheme. BMF 1993;307:1375.

21 Baker D, Klein R, Carter R. Impact of the 1990 contract for general practitioners on night visiting. $\mathrm{Br} \mathcal{f}$ Gen Pract 1994;44:68-71. 